\title{
DIFFERENCE BETWEEN MOTIVATIONAL GOAL FRAMING EFFECTS ON CREATIVE AND PERCEPTUAL TASK PERFORMANCE
}

\author{
Oshrit KASPI-BARUCH* \\ Achva Academic College, Department of Interdisciplinary Studies and Psychology, \\ MP Shikmim, Israel, 79800
}

Received 20 June 2018; accepted 19 October 2018

\begin{abstract}
This study examined the effects of motivational goal framing on creative and perceptual performance. Goal orientation was manipulated via task instructions. In order to examine whether goal framing (learning or performance) are influential only in creative performance, two experiments were conducted, one with creative task, the other with perceptual task. In the first experiment, 162 students engaged in full-time employment completed a creative task. In the second experiment, 268 students engaged in full-time employment completed a perceptual task. The first experiment showed that individuals instructed to be learning oriented were more creative relative to those instructed to be performance oriented. This occurred only in the creative task, as performance did not differ according to goal orientation framing in the second experiment. The results are discussed in terms of anxiety and cognitive performance theory and the stage model of creativity.
\end{abstract}

Keywords: creative performance, learning goal orientation, motivational goal orientation, perceptual performance, performance goal orientation.

\section{Introduction}

Individuals are motivated to pursue goals. According to the theory of goal orientation (GO), pursuing a certain goal can be done through either learning goal orientation (LGO) or performance goal orientation (PGO) (Dweck, 1989). LGO directs the individual to learn something new, or to enhance his or her qualifications in a certain activity. It is connected to mastery, learning, seeking challenges, and coping even in difficult conditions, and viewing failure as useful feedback accompanied by a positive emotion (Dweck, 1989, 2017). In contrast, PGO directs the individual toward goal achievement in terms of performance success and, as a result, it advocates avoidance of situations that lead to failure. Accordingly, goal achievement means receiving positive feedback following a successful performance, whereas negative feedback from failure is considered a negative outcome (Dweck, 1989). According to PGO, failure is attributed to lack of ability, and is consequently associated

${ }^{\star}$ Corresponding author. E-mail: oshrit_c@achva.ac.il 
with the experience of negative emotions and anxiety following failure. In turn, the anxiety associated with PGO has been found to impair performance, particularly in complex tasks (CoTs) that demand attention (Eysenck \& Calvo, 1992). Previous studies show inconsistencies regarding the effect of LGO on performance. In addition, the association between LGO and performance is affected by task type (Payne, Youngcourt, \& Beaubien, 2007). LGO has previously been shown to be beneficial to general performance (Button, Mathieu, Zajac, 1996; Farr, Hofmann, \& Ringenbach, 1993). However, it was found that PGO also enhanced performance (Bar-Eli, Tenenbaum, Pie, Btesh, \& Almog, 1997). In addition, PGO led to greater improvement in performance in simple tasks, relative to that observed for LGO (Steele-Johnson, Beauregard, Hoover, \& Schmidt, 2000). A perceptual task (PT), is a simple task. In contrast, a creative task (CT) is complex as more than a single answer is required. Thus it may be that PGO would lead to greater improvement in PT compared to CT. LGO was found to be beneficial to creative tasks (Gong, Huang, \& Farh, 2009; Hirst, Knippenberg, \& Zhou, 2009). In contrast, since PTs require vigilance, error detection, and focused attention, PGO could be beneficial, as it directs attention toward a specific goal. Therefore, it is possible that the effect of LGO may be different in creative tasks vs perceptual tasks. The current study's aim is to resolve the inconsistencies in previous findings and suggests it may be associated with the different contexts or tasks.

Thus, the purpose of this study was to examine the effects of motivational framing on performance in CTs and PTs. To establish causal relationships, an experimental design was used to determine whether creating a situation that emphasized learning, rather than performance, framing would increase creativity and this influence existed in other contexts (e.g., PTs). The study was important, as it examined means of enhancing creativity and sought to compare the benefit of motivational goal framing between CT and PT performance. As the effects of goal framing on performance could differ according to TT, the study included two experiments, one involving a CT and another involving a PT. Anxiety and cognitive performance theory (Eysenck, Derakshan, Santos, \& Calvo, 2007) and the stage model of creativity (Busse \& Mansfield, 1980; Cagle, 1985; Goswami, 1996; Ochse, 1990; Wallas, 1926) were used in this study to explain why the GO has a different effect on the performance of CTs versus $\mathrm{PTs}$.

\section{Literature review}

\subsection{Motivational goal framing}

GO theory is one of the theories that considers motivation in terms of goals. According to this theory, which is based on the social cognitive approach (Markus, 1977), motivation is connected to a goal. LGO, which directs towards learning and mastery of new skills, has a beneficial effect on performance, whereas PGO, which directs towards achievements and failure avoidance, has a harmful effect (Yperen, Van, Blaga, \& Postmes, 2014). LGO is positively related to performance in CTs (Seijts, Latham, Tasa, \& Latham, 2004); however, for other types of tasks, e.g., PTs, the effect of LGO on performance may be different. Indeed, it is reasonable to expect that the different GOs would have a different effect on task performance (TP), depending on the type of task involved. PTs are simple tasks of detection and counting. 
For instance, a stock keeper who monitors the goods in a warehouse needs to detect different kinds of goods (e.g., shoes, jackets, etc.) and then counts the items of each kind. In such a $\mathrm{PT}$, it is possible that LGO offers no advantage, because the task is very specific and simple.

Some researchers (DeShon \& Gillespie, 2005) divide GO into five categories: one of which is mental framework. This category refers to a broad range of beliefs, emotions, goals, and cognition, which have a varying influence in different achievement contexts. This category implies that GO can be situational; thus, it can be changed by manipulating one's beliefs, emotions, goals, and cognition. Numerous researchers have developed interventions designed to change GO (e.g., Kozlowski \& Bell, 2006; Gist \& Kay Stevens, 1998; Nicholls, 1984; Martocchio, 1994; Steele-Johnson et al., 2000; Kay Stevens, \& Gist, 1997). In the current study, GO was manipulated via the task instruction, either as LGO or PGO, as will be explained in the methods section.

Relative to PGO, LGO has been shown to be more beneficial to general performance (Moshman, 2018; Schraw, 2010). However, previous studies did not consider whether the effects of LGO and PGO depended on the task demands (Steele-Johnson et al., 2000). In addition, Michael Bar-Eli, Gershon Tenenbaum, Joan S. Pie, Yaacov Btesh and Asher Almog (1997) reported that students who received PGO instructions showed superior performance in muscular endurance sports relative to that of students who received LGO instructions. Additionally, a meta-analysis examining the influence of GOs according to the domain (e.g., education, industry, sports) found that LGO had a beneficial effect on performance, whereas PGO had a harmful effect, but this harmful effect was not found in the sports domain, probably because of the competitiveness of the field, in which performance orientation can be positive (Yperen et al., 2014). Therefore, it appears that LGO is not always superior to PGO in the context of performance, and manipulation of TT (e.g., creative versus perceptual) could be one means by which to illuminate this gap.

\subsubsection{Motivational goal framing and task type: creative task versus perceptual task}

One area in which GO might be especially relevant to performance is creativity. In the modern era, creativity is valued not only in the context of art but also in organizations that require innovation (Mumford \& Hunter, 2005; Zhou \& Shalley, 2008), which is considered vital for improving performance and achieving continuous competitive advantage (Anderson, Dreu, \& Nijstad, 2004; Liao \& Rice, 2010; Rosenbusch, Brinckmann, \& Bausch, 2011; Zhou \& Shalley, 2003). Creativity is multifaceted and defining it is complex and controversial (Acar, Burnett, \& Cabra, 2017). Nevertheless, in recent years scholars have agreed on two standards of creativity. The first involves characteristics of novelty and originality; the second involves usefulness, value, utility, effectiveness. Thus, a creative product is both original and useful (Runco \& Jaeger, 2012). Creativity involves two types of thinking, convergent thinking and divergent thinking (DT). Convergent thinking is usually relevant to questions that have one or very few specific correct answers. In contrast, DT is relevant to questions that are openended, to which various answers or solutions are possible (Runco, 2007).

Innovation and creativity involve a goal-directed process (West, 2002), as creativity typically stems from curiosity, which is associated with challenge-seeking goals (Alexander \& Knippenberg, 2014). LGO is relevant to creativity and innovation because a creative process 
requires exploring new directions, without fear of failure. By contrast, PGO may temper creativity since it directs the individual to final achievement accompanied with fear of failure which may hamper the creative processes (Gong \& Fan, 2006). Indeed, creativity was found to be associated with LGO (Gong et al., 2009; Hirst et al., 2009).

An understanding of means of developing creativity could enhance creative performance (CP), which has become important in the modern era. Intrinsic motivation has been shown to be crucial to creativity (Amabile, 1985; Amabile, Hennessey, \& Grossman, 1986). Therefore, the enhancement of creativity depends on structuring the work environment to engender personal engagement (Mumford, Scott, Gaddis, \& Strange, 2002). Although intrinsic motivation is important in the context of creativity, the role of goals is also relevant (Eisenberger \& Cameron, 1996).

The search for means to enhance employee creativity and to create optimal conditions for this process has become a major concern for many organizations and the identification of simple, short-term means of influencing creativity is important (Miron-Spektor \& Beenen, 2015). Some studies in innovation research have relied on participants' self-ratings for measuring dependent and/or independent variables (Anderson, Potočnik, \& Zhou, 2014); however, this has inherent shortcomings that lead to common method bias and construct validity concerns (Hülsheger, Anderson, \& Salgado, 2009). Therefore, enhancing our current knowledge regarding creativity requires the use of objective CP measures, as well as experimental settings that allow for causal conclusions to be drawn.

Amy Taylor-Bianco, E. Tory Higgins and Adena Klem (2003) reported that some tasks (e.g., those involving creativity) were associated with fun, while others (e.g., those involving error detection or counting) were associated with a sense of duty. They also found that performance improved when there was a fit between task perception (i.e., fun versus obligatory) and framing (i.e., instructions emphasizing fun versus duty). Indeed, some studies have demonstrated an association between LGO and creativity (Gong et al., 2009; Hirst et al., 2009); therefore, LGO could be beneficial in CTs. On the other hand, in PTs requiring detection or counting, PGO which is more associated to the final performance and therefore to a sense of duty, may be more suitable.

In the first experiment, a CT was used to assess the influence of GO on CP. LGO increases the numbers of strategies explored and knowledge domains used (Kozlowski \& Bell, 2006). It is also associated with challenge seeking (Janssen \& Yperen, 2004) and creativity (KaspiBaruch, Forthcoming). Theories that associate creativity with cognitive processes, such as DT, postulate that creativity requires exploration of new ways of thinking (Runco, 1991; Sternberg, 2017). Hence, LGO, which involves curiosity may foster new ways of thinking, thus, encouraging creativity. In the context of CP, LGO, which focuses on competence development, has been positively associated with individual engagement and creativity, while PGO, which focuses on gaining favorable external evaluations and outperforming others, has not (Gong \& Fan, 2006).

Several theoretical frameworks have been suggested for use in studying creativity. Early theories emphasized the innate characteristics of creativity and considered it a cognitive personality factor possessed by some individuals (e.g., Barron, 1961). Other theories considered the stages of the creative process. These models, which include both early (Wallas, 
1926) and contemporary models (e.g., Busse \& Mansfield, 1980; Cagle, 1985; Goswami, 1996; Ochse, 1990), described four stages of the creative process: preparation, incubation, illumination, and verification. Preparation involves problem identification (e.g., a product that is not purchased frequently requires a new marketing strategy). Incubation involves unconscious information processing, whereby the problem is temporarily put aside to allow new ideas and associations to occur. Illumination leads to insight regarding the problem and a solution. Incubation and illumination could produce better results in the context of LGO, as emphasis of the learning process, rather than results, could provide the time and relaxation required for incubation.

The stage model is relevant to the idea that individuals are more creative when they are relaxed, as noted by Hermann von Helmholtz, a physicist and physiologist, who reported that creative ideas came to mind while taking a break rather than sitting at a "working table" (as cited in Lubart, 2000-2001). When one is placed in an LGO state via manipulation of instructions, this could create a state of mind akin to that involved in taking a break away from one's "working table" and increase creativity. In contrast, when one is placed in a PGO state, the stress of being measured and the need to achieve could disrupt the incubation process, hampering illumination and creativity.

Some scholars have criticized the stage models, claiming that the stages are simultaneous rather than sequential (Cawelti, Rappaport, \& Wood, 1992). However, even if this is the case, incubation and illumination are important concepts in the context of creativity and are most likely to occur under LGO conditions, whereas one is probably more relaxed, given the stronger emphasis on process and the attenuated emphasis on the outcome. Therefore, LGO was expected to exert a positive influence on CP.

In addition, according to Maurizio Corbetta and Gordon L. Shulman (2002), there are two attentional systems: a top-down, goal-driven system, influenced by the individual's personal goals, expectations, and knowledge, and a bottom-up, stimulus-driven system, influenced by salient stimuli. According to attentional control theory (Eysenck et al., 2007), anxiety disrupts the balance between these two systems, by enhancing the influence of stimulus-driven, bottom-up processes over the efficient, top-down, goal-driven processes. Specifically, anxiety decreases the influence of the goal-directed attentional system and increases the influence of the stimulus-driven attentional system. Additionally, high anxiety was related to impaired performance with increased demands (Ashcraft \& Kirk, 2001). As a result, anxiety demands attention and disrupts top-down processing. Thus, the effects of anxiety on performance are greater in cases of tasks that impose considerable demands on central executive processes. According to attentional control theory (Eysenck et al., 2007), anxiety damages performance in CTs that demand attention. As creativity is complex and requires top-down processing, thus, creativity levels in the PGO condition are expected to be lower relative to those in the LGO condition.

Stage models of creativity were criticized for their failure to differentiate between creative and noncreative processes (Lubart, 2000-2001). Therefore, Experiment 2 included a PT designed to determine whether the influence of GO on performance occurred in PTs and improve understanding of the processes underlying non-CTs. Unlike CTs, which require higher and more complex levels of processing and integration, PTs are more perceptually driven, 
requiring processing of the physical features of stimuli (Jacoby, 1983; Roediger, 1990). In other words, or in terms of attentional control theory (Eysenck et al., 2007; Corbetta \& Shulman, 2002), CT requires top-down processing whereas PT requires bottom-up processing.

Some studies have found that LGO exerted a positive effect on perceptual performance (PP). For instance, in one study, students oriented toward learning exhibited higher grades relative to those of students oriented toward performance (Dweck \& Leggett, 1988); however, as achievement of good grades does not rely solely on perceptual reasoning, it is unclear whether LGO exerts a positive effect on PP. In addition, achievement in academic settings involves pursuit of both learning and performance (Barron \& Harackiewicz, 2001; Harackiewicz, Barron, Pintrich, Elliot, \& Thrash, 2002). PGO directs individuals toward goal achievement, performance success, receipt of positive feedback following success, and avoidance of negative feedback following failure. In contrast, LGO directs individuals toward learning or enhancement of their qualifications (Dweck, 1989). PTs require vigilance, error detection, and focused attention; therefore, PGO could be beneficial, as it directs attention toward a specific goal. Given that anxiety is viewed as enhancing performance of tasks that rely solely on the stimulus-driven attentional system, since anxiety enhances vigilance (Eysenck et al., 2007), it may be assumed that PGO will enhance performance in a PT, which is - by definition - stimulus driven. However, as LGO is related to challenge seeking and coping with difficult conditions, it could also exert a positive effect on PT performance. Therefore, the effects of PGO and LGO on PT performance were not expected to differ significantly.

A between-subject design was used in the present study (i.e., participants were assigned either a CT or a PT). This design was used to examine whether the effect of the manipulation would differ between various tasks. It could have been done in a repeated measures design, whereby the same participant would have been exposed to both types of tasks. However, in such a case, the two tasks types might have constituted a confounding variable. In addition, it would have created a significant load on each participant. Thus, two separate experiments were conducted, one involving the $\mathrm{CT}$ and the other involving the PT.

\subsubsection{Hypotheses}

Hypothesis 1: LGO framing will produce greater creativity relative to that produced by PGO framing.

Hypothesis 2: PT performance will not differ according to framing orientation.

\subsubsection{Method}

Sample and design. In total, 162 (46\% men) bachelor of arts students enrolled on a business administration program in Israel participated in the first experiment. Respondents' mean age was 32.9 years. In total, 216 (28\% men) bachelor of arts Students enrolled on a business administration program in Israel participated in the second experiment. Respondents' mean age was 26.8 years. All participants were of Jewish-Israeli nationality, and as the course was designed for employed individuals, they were all engaged in full-time employment. They received extra course credit in return for their participation. The manipulation received ethics committee approval, as it involved deception and could have evoked negative feelings (particularly the performance condition); participants received an explanation regarding the 
true purpose of the experiment upon completion. Participants who experienced discomfort were encouraged to consult the researcher further, but none of them did so.

Procedure and manipulation. A between-subjects model was created, and the experimental sessions were conducted via Qualtrics online software (2018). An invitation to participate in the experiments was sent via e-mail through the course website. All participants provided informed consent, and completion of the tasks and questionnaires took 20-30 min. Participants were randomly assigned to the experimental and control groups via the computer software; therefore, masking was assured. In addition, the experimenter and participants were blind to the conditions. The items were randomized, and participants' anonymity was assured.

The manipulation of goal framing was performed via the task instructions and based on those described by John Graham Nicholls (1984, as cited in Steele-Johnson et al., 2000). Participants in the LGO condition were provided with the following instructions.

This task examines learning and skill development over time. The task is built in such a way that your learning ability will improve according to the amount of effort you put in. This task will help you to develop your skills and capabilities. The result is less important than the learning process and the extent of your personal improvement.

In contrast, participants in the PGO condition were provided with the following instructions: The task examines stable, fixed mental ability. The task is built in such a way that your performance reflects your mental ability. The task is a measure of your ability and achievements; therefore, the result and number of correct answers are important. Your achievements will be compared to those of other people.

Participants in the control condition completed the task with no manipulation and were provided with the regular CT instructions (e.g., "Please describe all of the things that can be done with a box").

Task and measures. In the first experiment, $\mathrm{CP}$ was measured according to the instructions of the authors of the Tel Aviv Creativity Test (TACT) (R. M. Milgram \& N. A. Milgram, 1976). The task included four items: two verbal items (e.g., "Please describe all of the things that can be done with a box" and "Please describe all the things that can be done with a newspaper") and two involving shapes (e.g., "Please describe all of the things that this shape could represent", where two abstract shapes are shown). Participants could provide 15 possible responses, each worth one point, for each item in each of the four questions. For instance, in reply to the question, "Please describe all the things that can be done with a newspaper?" they might answer, "Clean with it, make a hat of it", etc. For each answer they received 1 point; thus, had the maximal score on each question was 15 points. One additional point was awarded for each original answer. An original answer was defined as an answer provided by $<5 \%$ of participants. As there were four items, the maximum score was 120 (60 for the number of uses and 60 for originality). Thus, the TACT consists of two dimensions of creativity, quantity (measured by the number of answers) and quality (measured by the originality of the answers).

In the second experiment, a PT was designed for use in the experiment. Since the CT in Experiment 1 consisted of 4 items, the PT in Experiment 2 also consisted of four questions. Each of the questions was presented on a screen showing various shapes, and partici- 


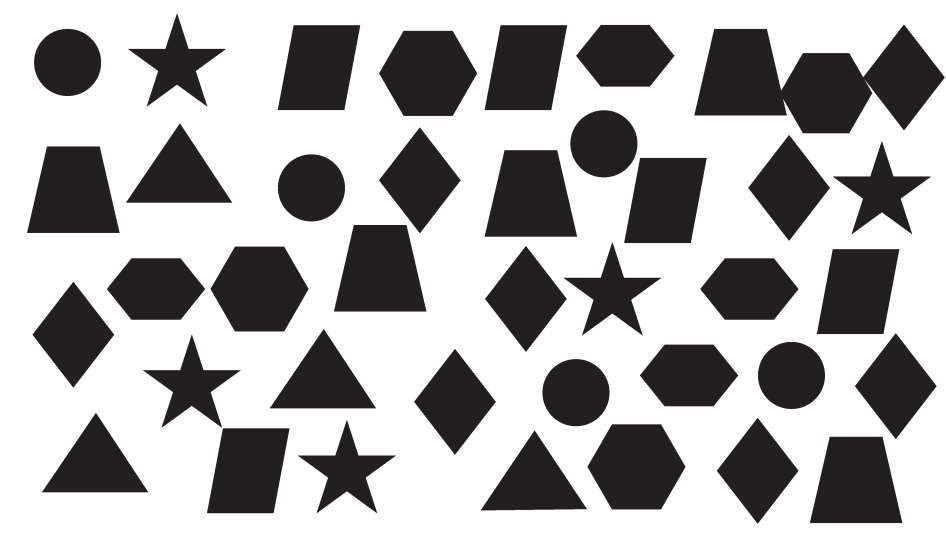

Figure 1. Examples of the shapes that appeared in the task (source: crated by authors)

pants were required to count the number of times a shape appeared. For instance, an array of shapes (e.g., circles, triangles, and squares), within which eight triangles were scattered, was presented on the screen, and participants were required to count the triangles. Given that one of the aims of the study was to examine the effect of GO in different contexts, e.g., creative and non-creative, the PT was used because it is very different from the CT used in the first study. In contrast to the CT used in Experiment 1, in which numerous possible answers were applicable, and an open mind, DT and creativity were required, the task in Experiment 2 was perceptual and involved only one correct answer (e.g., eight). Hence, this task required convergent-type thinking. The specific task used in this study included counting simple forms, e.g. triangular. A visual PT was used, because visual perception involves simple perceptual mechanisms, compared to the higher cognitive processes required in the CT. Successful completion of the task required vigilance, attention to detail, and avoidance of mistakes, as there was only one correct answer; high scores were achieved by avoiding mistakes and providing the correct answer. PP was measured according to the number of correct answers provided. If participants counted the number of shapes correctly for a question, they received one point. As the task included four questions, the maximum score was 4. Examples of the shapes that appeared in the task are shown in Figure 1.

\subsubsection{Results}

Manipulation check. The manipulation check determined whether participants understood the instructions, to allow exclusion of those who did not. Upon completion of the experiment, participants were asked to indicate what was measured in the experiment (i.e., learning, performance, or other). In the first experiment, of the original 162 participants, 129 (79\%) perceived the manipulation correctly (those in the learning condition stated that the experiment measured learning, and those in the performance condition stated that it measured performance). As the control condition did not involve manipulation, all the participants in the control group were included. 
Another manipulation check conducted was to measure GO after the task was completed and examine whether the manipulation changed participants' GO. In no case was a significant change in orientation found because of the manipulation (LGO: $F(2,117)=0.15, p=$ NS; PGO: $F(2,117)=0.44, p=\mathrm{NS})$. However, given the robustness and stability of those constructs, it is not surprising.

In the second experiment, Of the original 268 participants, $216(80 \%)$ perceived the manipulation correctly (those in the learning condition stated that the experiment measured learning, and those in the performance condition stated that it measured performance). As the control condition did not involve manipulation, all participants in the control group were included.

As in the first experiment, another manipulation check conducted was to measure GO after the task was completed and to examine whether the manipulation changed participants' GO. LGO and PGO were not significantly changed because of the different conditions of the manipulation (LGO: $F(2,213)=0.92, p=\mathrm{NS}$; PGO: $F(2,213)=0.88, p=\mathrm{NS}$ ). However, as mentioned in the first experiment, given the robustness and stability of those constructs it is not surprising.

In the first experiment, a one-way between-groups ANOVA was performed to analyze the data of the first experiment. As expected, the manipulation affected participants' creativity, $F(2,129)=7.93, p<.001, \eta^{2}=0.11$. Participants who received the learning-related instructions were more creative $(M=32.4, S D=21, n=36)$ relative to those who received the performance-related instructions $(M=17, S D=8.95, n=34)$. Contrast analysis revealed a significant difference between the learning and performance manipulation, $t(1,126)=4.00$, $p<.001, d=1.00,95 \%$ CI $[-5.83,4.02]$. However, contrast analysis comparing control and treatment (learning and performance) did not reveal a significant difference in this regard, $t$ $(1,126=.11, p=.91)$. Levels of creativity exhibited by participants in the control group $(M=$ $25, S D=17, n=59$ ) did not differ from those of participants in the learning or performance conditions. The findings are presented in Figure 2.

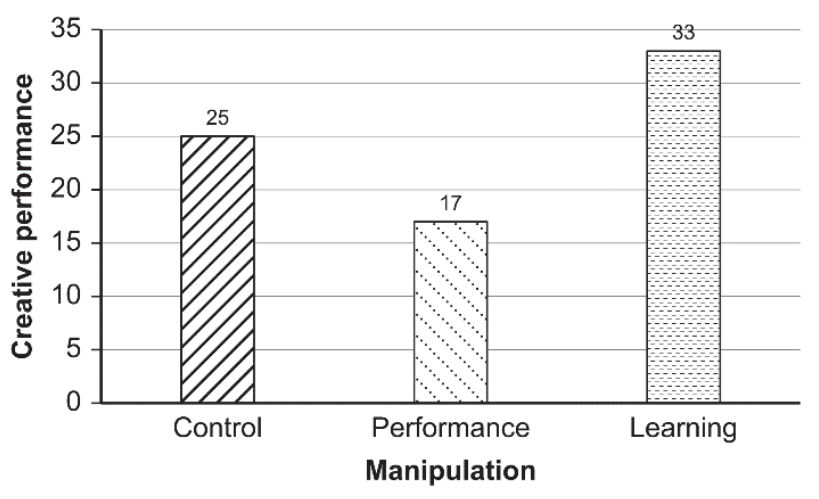

$\mathrm{F}(2,129)=7.93, \mathrm{p}<0.001, \eta^{2}=0.11$

Figure 2. Means of creative performance as a function of motivational orientation (source: created by authors) 
A one-way between-groups ANOVA was used to analyze the data of the second experiment. As expected the manipulation did not affect performance, $F(2,215)=0.60, p=.54$, $\eta^{2}=0.006$. The performance of participants' who received the learning-related instructions $(M=2.90, S D=0.92, n=72)$ did not differ significantly relative to that of those who received the performance-related instructions $(M=2.80, S D=0.98, n=68)$ or those in the control group $(M=2.71, S D=1.03, n=76)$.

\subsubsection{Discussion}

In the first experiment, as expected, framing that oriented participants toward learning increased their creativity relative to that observed for framing that oriented them toward performance. Therefore, LGO was positively associated with creativity, while PGO was negatively associated with it. The results showed that LGO was positively associated with $\mathrm{CP}$, as reported in previous studies (e.g., Gong et al., 2009; Hirst et al., 2009).

In addition to demonstrating the association between LGO and creativity, the results elucidated the situational effect of LGO on creativity. Several studies, the first of which was conducted by the Institute of Personality Assessment and Research (now Institute of Personality and Social Research, University of California, Berkeley) (e.g., Barron, 1972; Helson, 1999; MacKinnon, 1962), have attempted to identify personality correlates for creativity. Others have criticized attempts to associate personality with creativity, suggesting that the correlation between personality and creativity is weak, and there is no such thing as a creative personality (Nęcka \& Hlawacz, 2013). Theoretically, the results of Experiment 1 indicated that creativity was not limited to individuals with particular personalities and could be altered by creating the right situations (e.g., those involving learning orientation). Regardless of whether the creative personality exists, it is clear that it is possible to enhance creativity by changing the situation. Individuals with high LGO levels seek opportunities to enhance future knowledge and skills (VandeWalle, 2001). Therefore, LGO is positively associated with creativity. In contrast, PGO has been associated with anxiety and achievement preservation rather than learning (Chen, Gully, Whiteman, \& Kilcullen, 2000; Payne et al., 2007). Therefore, learning-oriented environments encourage individuals to seek new ways via which to learn and enhance their knowledge, increasing their creativity. In contrast, environments that emphasize performance could limit the pursuit of new challenges and encourage individuals to remain "safe" to achieve results, decreasing their creativity. Indeed, some studies have demonstrated that levels of creativity were low when individuals expected to be evaluated according to certain standards (Amabile, 1979; Baer, 1997).

Theoretically, these findings are consistent with stage models of creativity (Busse \& Mansfield, 1980; Cagle, 1985; Goswami, 1996; Ochse, 1990; Wallas, 1926), as incubation and illumination are enhanced when individuals are free of obligation concerning final performance (e.g., when one is less performance oriented and open to learning). Therefore, creating situations in which individuals are learning oriented could enhance incubation and allow the illumination required for creativity to occur. In contrast, consistent with attentional control theory (Eysenck et al., 2007), creating situations in which individuals are performance oriented could hamper incubation, as anxiety rising due to comparison with others and pressure to improve performance interfere with maturation. Therefore, blocking illumination decreases creativity, as demonstrated in the PGO condition. 
Practically, these findings imply that creativity can be enhanced in a simple and elegant manner; all that is required is framing of the situation in a way that encourages challenge seeking and learning. As PGO diminishes creativity, we should also avoid emphasizing performance and results, if increased creativity is desired. This finding has important implications for educational and organizational settings. Educators, managers, and practitioners should frame learning goals for students or employees in a manner that emphasizes the learning process and opportunities rather than achievement and performance.

It is important to mention that the validity of the findings was undermined, as no difference was observed between the control and treatment (LGO and PGO) groups. One explanation for this pattern could involve the nature of the task. The experiment included CT in which participants were asked to describe various uses of an object (i.e., a box). However, this could have oriented participants toward learning. Given that participants in the control group received no specific instructions other than the regular CT ones, it is possible that the nature of the CT encouraged their learning orientation; however, it is also possible that wanting to succeed in the task also oriented them towards performance. Therefore, it might be that both levels of LGO and PGO in the control group were elevated to a similar extent. Thus, although LGO was not manipulated in the control group, it may be that the participants were learning oriented in a similar way to the ones in the LGO treatment and the same occurred for the control and the PGO treatment. Of course, it can be argued that if no difference was found between the control and the experiment, it is difficult to claim that the manipulation influenced performance. Nevertheless, the fact that CP was elevated in the LGO condition and was significantly lower in the PGO condition suggests that being learning oriented is positively associated with creativity and being performance oriented is negatively associated with creativity. In the second experiment, as expected, PT performance did not differ according to whether participants received the learning or performance instructions. Previous studies reported that LGO led to greater improvement in performance relative to that observed for PGO (e.g., Dweck \& Leggett, 1988); however, these findings were observed in the context of academic achievement, which requires other types of reasoning in addition to that of a perceptual nature (Barron \& Harackiewicz, 2001; Harackiewicz et al., 2002). The lack of difference in performance between the LGO and PGO conditions indicates that PT performance was not influenced by framing. One reason for this finding could be that, as the PT involved only one correct answer, completion required focus, vigilance, and avoidance of mistakes. PGO could aid in the fulfillment of these requirements, as it focuses attention on performance, target detection, and the avoidance of mistakes. However, according to the theory of anxiety and cognitive performance (Eysenck et al., 2007), PGO could also hamper performance, as it is associated with anxiety and requires attention. In addition, improving one's strategy for providing the correct solution and being able to learn, improve skills, and learn from mistakes could also be of benefit. In other words, LGO could be beneficial, as placing individuals in situations that encourage learning and skill development could help them to identify superior means of determining the correct solution and improving performance. Therefore, it appears that LGO and PGO exert similar effects in PTs.

Practically, the findings indicated that it does not matter whether framing is learning or performance oriented in PTs. This suggests that, in PTs in educational settings, teachers could create 
either a learning-oriented environment, emphasizing the process and importance of learning, or a performance-oriented environment, emphasizing results and the importance of grades, as orientation will not affect students' performance (e.g., solving mathematical exercises). Similarly, in organizational settings, managers could emphasize the importance of learning from mistakes and enhancing skills, or performance measurement and comparison with others, as orientation will not affect employees' performance in PTs (e.g., checking inventory or balancing accounts).

\section{Limitations and future research}

The study was subject to several limitations; therefore, the findings should be interpreted with caution. First, the sample included only students, which undermined the external validly of the study. Future studies should recruit broader samples that include employees from organizations and students from educational settings. Second, the CT included a fluency part, which was criticized as an insufficient measure of creativity (Silvia, Nusbaum, \& Beaty, 2017). As Mark Runco stated, fluency is not as closely tied to creativity as is originality (Beketayev \& Runco, 2016). Nevertheless, the scores on the CTs were based also on originality, which bolsters the validity of the measure used in the current study.

Third, the CT was verbal, and the PT involved visual perception. The difference in the task modalities could have created an artefact that affected the results. Tasks using similar modalities could produce different results. In the future, additional tasks should be used to examine the interaction between the task and the effect of task modality. In addition, various real-life, rather than laboratory-based, tasks should be used. For instance, tasks involving marketing-related thinking could produce different results to those produced by tasks involving scientific or artistic creativity.

\section{Conclusions}

Two experiments were conducted to examine the effects of GO on performance. Instructions framed to provide LGO led to a greater improvement in CP relative to that observed when instructions were framed to provide PGO. This effect did not occur in the PT. Therefore, it seems that LGO is positively associated with performance in the CT, but not with the perceptual one. These findings are consistent with those of previous studies that reported a positive association between LGO and creativity and a negative association between PGO and creativity (e.g., Gong et al., 2009; Hirst et al., 2009).

The second experiment used a PT to determine whether the beneficial influence of LGO on performance was general or exclusive to CP. The lack of difference in performance between the LGO and PGO conditions in the second experiment, indicated that LGO is associated with performance in the $\mathrm{CT}$, but not with $\mathrm{PT}$ performance.

Theoretically, these findings are important, as they clarify the inconsistencies in the literature regarding the effect of GO on performance. LGO has previously been shown to be beneficial to general performance (Button et al., 1996; Farr et al., 1993). However, researchers (e.g., Bar-Eli et al., 1997) reported that students who received PGO instructions exhibited superior performance relative to that of those who received LGO instructions. In addition, Debra Steele- 
Johnson, Russell S. Beauregard, Paul B. Hoover and Aaron M. Schmidt (2000) found that PGO led to greater improvement in performance, relative to that observed for LGO, in simple tasks. The results of the current study suggested that the inconsistencies in previous findings were related to differences between contexts or tasks. As shown in the first experiment, LGO exerts a positive effect and PGO exerts a negative effect on performance in CTs. This effect was not observed in the PT, indicating that LGO did not exert a beneficial effect on PP.

Why does LGO exert a positive effect in creative, but not perceptual, contexts? According to attentional control theory (Eysenck et al., 2007), PGO is associated with anxiety that impairs performance. This distraction occurs in CP, because it is complex and demands attention. This could explain why creativity levels were higher in the LGO condition and lower in the PGO condition in Experiment 1. Why was no difference in performance observed between the LGO and PGO conditions in the PT in Experiment 2? The PT was simple and demanded little attention; therefore, the level of interference caused by anxiety in Experiment 2 was lower relative to that observed in Experiment 1. In addition, as expected considering attentional control theory (Eysenck et al., 2007), which states that anxiety may disrupt topdown processing and given that creativity is complex and requires top-down processing, creativity levels in the PGO condition were lower relative to those observed in the LGO condition. However, as PGO affects higher processing, it did not diminish performance in the PT, which was simple and did not require higher processing. Additionally, anxiety caused in the PGO condition, may even have a positive effect on performance in PTs since it enhances vigilance thus assisting in shapes detection (Eysenck et al., 2007). Nevertheless, since LGO may also assist in recognition of shapes thus enhance performance, no difference was found in performance in the LGO and PGO condition.

Practically, this implies that enhancement of creativity is possible through the creation of a learning-oriented environment involving creative contexts and tasks. However, in perceptual contexts and tasks, framing was unimportant.

It is important to mention that the anxiety levels of the participants were measured after the manipulation; however, as no significant differences were found in the anxiety levels in the different conditions of the manipulations (e.g., LGO, PGO and control), it is difficult to be sure that the PGO manipulation is the factor that exerted more anxiety. Hence, this result, thus undermines the explanation of the attentional control theory (Eysenck et al., 2007). However, because anxiety level was assessed using only a single subjective item, it is possible that more objective measures would have revealed more conclusive results.

\section{References}

Acar, S., Burnett, C., \& Cabra, J. F. (2017). Ingredients of creativity: originality and more. Creativity Research Journal, 29(2), 133-144. https://doi.org/10.1080/10400419.2017.1302776

Alexander, L., \& Knippenberg, van D. (2014). Teams in pursuit of radical innovation: a goal orientation perspective. Academy of Management Review, 39(4), 423-438. https://doi.org/10.5465/amr.2012.0044

Amabile, T. M. (1979). Effects of external evaluation on artistic creativity. Journal of Personality and Social Psychology, 37(2), 221-233. https://doi.org/10.1037/0022-3514.37.2.221

Amabile, T. M. (1985). Motivation and creativity: effects of motivational orientation on creative writers. Journal of Personality and Social Psychology, 48(2), 393-399.

https://doi.org/10.1037/0022-3514.48.2.393 
Amabile, T. M., Hennessey, B. A., \& Grossman, B. S. (1986). Social Influences on creativity: the effects of contracted-for reward. Journal of Personality and Social Psychology, 50(1), 14-23. https://doi.org/10.1037/0022-3514.50.1.14

Anderson, N., Dreu, De C. K. W., \& Nijstad, B. A. (2004). The routinization of innovation research: a constructively critical review of the state-of-the-science. Journal of Organizational Behavior, 25(2), 147-173. https://doi.org/10.1002/job.236

Anderson, N., Potočnik, K., \& Zhou, J. (2014). Innovation and creativity in organizations: a state-of-thescience review, prospective commentary, and guiding framework. Journal of Management, 40(5), 1297-1333. https://doi.org/10.1177/0149206314527128

Ashcraft, M. H., \& Kirk, E. P. (2001). The relationships among working memory, math anxiety, and performance. Journal of Experimental Psychology: General, 130(2), 224-237.

https://doi.org/10.1037/0096-3445.130.2.224

Bar-Eli, M., Tenenbaum, G., Pie, J. S., Btesh, Y., \& Almog, A. (1997). Effect of goal difficulty, goal specificity and duration of practice time intervals on muscular endurance performance. Journal of Sports Sciences, 15(2), 125-135. https://doi.org/10.1080/026404197367407

Baer, J. (1997). Gender differences in the effects of anticipated evaluation on creativity. Creativity Research Journal, 10(1), 25-31. https://doi.org/10.1207/s15326934crj1001_3

Barron, F. (1972). Artists in the making. New York: Seminar Press.

Barron, F. (1961). Creative vision and expression in writing and painting. In D. W. MacKinnon (Ed.), The Creative Person (pp. 237-251). Berkeley, CA: Institute of Personality Assessment Research, University of California.

Barron, K. E., \& Harackiewicz, J. M. (2001). Achievement goals and optimal motivation: testing multiple goal models. Journal of Personality and Social Psychology, 80(5), 706-722.

https://doi.org/10.1037/0022-3514.80.5.706

Beketayev, K., \& Runco, M. A. (2016). Scoring divergent thinking tests by computer with a semanticsbased algorithm. Europe's Journal of Psychology, 12(2), 210-220. https://doi.org/10.5964/ejop.v12i2.1127

Busse, Th. V., \& Mansfield, R. S. (1980). Theories of the creative process: a review and a perspective. Journal of Creative Behavior, 14(2), 91-132. https://doi.org/10.1002/j.2162-6057.1980.tb00232.x

Button, S. B., Mathieu, J. E., \& Zajac, D. M. (1996). Goal orientation in organizational research: a perceptual and empirical foundation. Organizational Behavior and Human Decision Processes, 67(1), 26-48. https://doi.org/10.1006/obhd.1996.0063

Cagle, M. (1985). A general abstract-concrete model of creative thinking. Journal of Creative Behavior, 19(2), 104-109. https://doi.org/10.1002/j.2162-6057.1985.tb00643.x

Cawelti, S., Rappaport, A., \& Wood, B. (1992). Modeling artistic creativity: an empirical study. Journal of Creative Behavior, 26(2), 83-94. https://doi.org/10.1002/j.2162-6057.1992.tb01164.x

Chen, G., Gully, S. M., Whiteman, J.-A., \& Kilcullen, R. N. (2000). Examination of relationships among trait-like individual differences, state-like individual differences, and learning performance. Journal of Applied Psychology, 85(6), 835-847. https://doi.org/10.1037/0021-9010.85.6.835

Corbetta, M., \& Shulman, G. L. (2002). Control of goal-directed and stimulus-driven attention in the brain. Nature Reviews: Neuroscience, 3, 201-215. https://doi.org/10.1038/nrn755

DeShon, R. P., \& Gillespie, J. Z. (2005). A motivated action theory account of goal orientation. Journal of Applied Psychology, 90(6), 1096-1127. https://doi.org/10.1037/0021-9010.90.6.1096

Dweck, C. S. (2017). From needs to goals and representations: foundations for a unified theory of motivation, personality, and development. Psychological Review, 124(6), 689-719. https://doi.org/10.1037/rev0000082

Dweck, C. S. (1989). Motivation. In A. Lesgold, \& R. Glaser (Eds.), Foundations for a Psychology of Education (pp. 87-136). New Jersey: Lawrence Erlbaum Associates, Inc., Publishers. 
Dweck, C. S., \& Leggett, E. L. (1988). A social-cognitive approach to motivation and personality. Psychological Review, 95(2), 256-273. https://doi.org/10.1037/0033-295X.95.2.256

Eisenberger, R., \& Cameron, J. (1996). Detrimental effects of reward: reality or myth? American Psychologist, 51(11), 1153-1166. https://doi.org/10.1037/0003-066X.51.11.1153

Eysenck, M. W., \& Calvo, M. G. (1992). Anxiety and performance: the processing efficiency theory. Cognition and Emotion, 6(6), 409-434. https://doi.org/10.1080/02699939208409696

Eysenck, M. W., Derakshan, N., Santos, R., \& Calvo, M. G. (2007). Anxiety and cognitive performance: attentional control theory. Emotion, 7(2), 336-353. https://doi.org/10.1037/1528-3542.7.2.336

Farr, J. L., Hofmann, D. A., \& Ringenbach, K. L. (1993). Goal orientation and action control theory: implications for industrial and organizational psychology. In C. L. Cooper, \& I. T. Robertson (Eds.), International Review of Industrial and Organizational Psychology, 8, 193-232. New York: John Wiley \& Sons, Ltd.

Gist, M. E., \& Kay Stevens, C. (1998). Effects of practice conditions and supplemental training method on cognitive learning and interpersonal skill generalization. Organizational Behavior and Human Decision Processes, 75(2), 142-169. https://doi.org/10.1006/obhd.1998.2787

Gong, Y., \& Fan, J. (2006). Longitudinal examination of the role of goal orientation in cross-cultural adjustment. Journal of Applied Psychology, 91(1), 176-184. https://doi.org/10.1037/0021-9010.91.1.176

Gong, Y., Huang, J.-Ch., \& Farh, J.-L. (2009). Employee learning orientation, transformational leadership, and employee creativity: the mediating role of employee creative self-efficacy. Academy of Management Journal, 52(4), 765-778. https://doi.org/10.5465/amj.2009.43670890

Goswami, A. (1996). Creativity and the quantum: a unified theory of creativity. Creativity Research Journal, 9(1), 47-61. https://doi.org/10.1207/s15326934crj0901_5

Harackiewicz, J. M., Barron, K. E., Pintrich, P. R., Elliot, A. J., \& Thrash, T. M. (2002). Revision of Achievement Goal Theory: necessary and illuminating. Journal of Educational Psychology, 94(3), 638-645. https://doi.org/10.1037/0022-0663.94.3.638

Helson, R. (1999). A longitudinal study of creative personality in women, Creativity Research Journal, 12(2), 89-101. https://doi.org/10.1207/s15326934crj1202_2

Hirst, G., Knippenberg, van D., \& Zhou, J. (2009). A cross-level perspective on employee creativity: goal orientation, team learning behavior, and individual creativity. Academy of Management Journal, 52(2), 280-293. https://doi.org/10.5465/amj.2009.37308035

Hülsheger, U. R., Anderson, N., \& Salgado, J. F. (2009). Team-level predictors of innovation at work: a comprehensive meta-analysis spanning three decades of research. Journal of Applied Psychology, 94(5), 1128-1145. https://doi.org/10.1037/a0015978

Jacoby, L. L. (1983). Remembering the data: analyzing interactive processes in reading. Journal of Verbal Learning and Verbal Behavior, 22(5), 485-508.

Janssen, O., \& Yperen, Van N. W. (2004). Employees' goal orientations, the quality of leader-member exchange, and the outcomes of job performance and job satisfaction. Academy of Management Journal, 47(3), 368-384.

Kay Stevens, C., \& Gist, M. E. (1997). Effects of self-efficacy and goal-orientation training on negotiation skill maintenance: what are the mechanisms? Personnel Psychology, 50(4), 955-978.

Kaspi-Baruch, O. (Forthcoming). Big Five personality and creativity: the moderating effect of motivational goal orientation, The Journal of Creative Behavior. https://doi.org/10.1002/jocb.183

Kozlowski, S. W. J., \& Bell, B. S. (2006). Disentangling achievement orientation and goal setting: effects on self-regulatory processes. Journal of Applied Psychology, 91(4), 900-916.

Liao, T. Sh., \& Rice, J. (2010). Innovation investments, market engagement and financial performance: a study among Australian manufacturing SMEs. Research Policy, 39(1), 117-125.

Lubart, T. I. (2000-2001). Models of the creative process: past, present and future. Creativity Research Journal, 13(3-4), 295-308. https://doi.org/10.1016/j.respol.2009.11.002 
MacKinnon, D. W. (1962). The nature and nurture of creative talent. American Psychologist, 17(7), 484495. https://doi.org/10.1037/h0046541

Martocchio, J. J. (1994). Effects of conceptions of ability on anxiety, self-efficacy, and learning in training. Journal of Applied Psychology, 79(6), 819.

Markus, H. (1977). Self-schemata and processing information about the self. Journal of Personality and Social Psychology, 35(2), 63-78.

Milgram, R. M., \& Milgram, N. A. (1976). Creative thinking and creative performance in Israeli students. Journal of Educational Psychology, 68(3), 255-259. https://doi.org/10.1037/0022-0663.68.3.255

Miron-Spektor, E., \& Beenen, G. (2015). Motivating creativity: the effects of sequential and simultaneous learning and performance achievement goals on product novelty and usefulness. Organizational Behavior and Human Decision Processes, 127, 53-65. https://doi.org/10.1016/j.obhdp.2015.01.001

Mumford, M. D., \& Hunter, S. T. (2005). Innovation in organizations: a multi-level perspective on creativity. In F. Dansereau, \& F. J. Yammarino (Eds.), Multi-level issues in strategy and methods. Vol. 4: Research in Multi-Level Issues (pp. 11-74). Amsterdam: Elsevier Ltd. https://doi.org/10.1016/S1475-9144(05)04001-4

Mumford, M. D., Scott, G. M., Gaddis, B., \& Strange, J. M. (2002). Leading creative people: orchestrating expertise and relationships. The Leadership Quarterly, 13(6), 705-750.

https://doi.org/10.1016/S1048-9843(02)00158-3

Moshman, D. (2018). Metacognitive theories revisited. Educational Psychology Review, 30(2), 599-606. https://doi.org/10.1007/s10648-017-9413-7

Nęcka, E., \& Hlawacz, T. (2013). Who has an artistic temperament? Relationships between creativity and temperament among artists and bank officers. Creativity Research Journal, 25(2), 182-188. https://doi.org/10.1080/10400419.2013.783744

Nicholls, J. G. (1984). Achievement motivation: conceptions of ability, subjective experience, task choice, and performance. Psychological Review, 91(3), 328-346. https://doi.org/10.1037/0033-295X.91.3.328

Ochse, R. (1990). Before the gates of excellence: the determinants of creative genius. Cambridge: Cambridge University Press.

Payne, S. C., Youngcourt, S. S., \& Beaubien, J. M. (2007). A meta-analytic examination of the goal orientation nomological net. Journal of Applied Psychology, 92(1), 128-150. https://doi.org/10.1037/0021-9010.92.1.128

Qualtrics. (2018). Qualtrics. Retrieved from https://www.qualtrics.com/?drift=2

Roediger, III H. L. (1990). Implicit memory: retention without remembering. American Psychologist, 45(9), 1043-1056. https://doi.org/10.1037/0003-066X.45.9.1043

Rosenbusch, N., Brinckmann, J., \& Bausch, A. (2011). Is innovation always beneficial? A meta-analysis of the relationship between innovation and performance in SMEs. Journal of Business Venturing, 26(4), 441-457. https://doi.org/10.1016/j.jbusvent.2009.12.002

Runco, M. A. (2007). Creativity. Theories and themes: research, development, and practice. San Diego, CA: Elsevier Academic Press.

Runco, M. A. (1991). Divergent thinking. Norwood, NJ: Ablex Publishing Corporation.

Runco, M. A., \& Jaeger, G. J. (2012). The standard definition of creativity. Creativity Research Journal, 24(1), 92-96. https://doi.org/10.1080/10400419.2012.650092

Schraw, G. (2010). On the development of adult metacognition. In M. C. Smith, \& Th. Pourchot (Eds.), Adult learning and development: perspectives from educational psychology (pp. 89-106). New York: Routledge.

Seijts, G. H., Latham, G. P., Tasa, K., \& Latham, B. W. (2004). Goal setting and goal orientation: an integration of two different yet related literatures. Academy of Management Journal, 47(2), 227-239.

Silvia, P. J., Nusbaum, E. C., \& Beaty, R. E. (2017). Old or new? Evaluating the old/new scoring method for divergent thinking tasks. Journal of Creative Behavior, 51(3), 216-224.

https://doi.org/10.1002/jocb.101 
Steele-Johnson, D., Beauregard, R. S., Hoover, P. B., \& Schmidt, A. M. (2000). Goal orientation and task demand effects on motivation, affect, and performance. Journal of Applied Psychology, 85(5), 724-738. https://doi.org/10.1037/0021-9010.85.5.724

Sternberg, R. J. (2017). Whence creativity? Journal of Creative Behavior, 51(4), 289-292. https://doi.org/10.1002/jocb.199

Taylor-Bianco, A., Higgins, E. T., \& Klem, A. (2003). How "Fun/Importance" fit affects performance: relating implicit theories to instructions. Personality and Social Psychology Bulletin, 29(9), 10911103. https://doi.org/10.1177/0146167203253481

VandeWalle, D. (2001). Goal orientation: why wanting to look successful doesn't always lead to success. Organizational Dynamics, 30(2), 162-171. https://doi.org/10.1016/S0090-2616(01)00050-X

Wallas, G. (1926). The art of thought. New York, NY: Harcourt, Brace and Company.

West, M. A. (2002). Sparkling fountains or stagnant ponds: an integrative model of creativity and innovation implementation in work groups. Applied Psychology, 51(3), 355-387. https://doi.org/10.1111/1464-0597.00951

Yperen, Van N. W., Blaga, M., \& Postmes, T. (2014). A meta-analysis of self-reported achievement goals and nonself-report performance across three achievement domains (work, sports, and education). PloS One, 9(4), 1-16. https://doi.org/10.1371/journal.pone.0093594

Zhou, J., \& Shalley, Ch. E. (Eds.). (2008). Handbook of organizational creativity. New York, NY: Taylor \& Francis Group, LLC.

Zhou, J., \& Shalley, Ch. E. (2003). Research on employee creativity: a critical review and directions for future research. In M. R. Buckley, J. R. B. Halbesleben, \& A. R. Wheeler (Series Eds.), Research in Personnel and Human Resources Management (pp. 165-217). Vol. 22. Bingley: Emerald Group Publishing Limited. https://doi.org/10.1016/S0742-7301(03)22004-1

\title{
MOTYVUOJANČIO TIKSLO FORMULAVIMO İTAKOS SKIRTINGUMAS ATLIEKANT KŪRYBINĘ IR SUVOKIMO UŽDUOTI
}

\section{Oshrit KASPI-BARUCH}

\begin{abstract}
Santrauka
Šiame tyrime nagrinejjama skirtinga motyvuojančio tikslo ịtaka kūrybinei ir suvokimo veiklai. Orientavimasis ị tikslus buvo valdomas užduočių instrukcijomis. Siekiant išanalizuoti, ar tikslo formulavimas (mokymasis ar veikla) turi įtakos tik kūrybinei veiklai, buvo atlikti du eksperimentai: vienas - pasitelkiant kūrybinę užduotị, kitas suvokimo užduotị. Pirmajame eksperimente 162 studentai visą eksperimento laiką atliko kūrybinę užduotị, antrajame eksperimente 268 studentai visą eksperimento laiką atliko suvokimo užduotị. Pirmuoju eksperimentu buvo atskleista, kad asmenys, kuriems buvo nurodyta orientuotis į mokymąsi, buvo kūrybiškesni, palyginti su tais, kurie turejo orientuotis ị veiklą. Taip įvyko tik duodant kūrybinę užduotị, nes antrojo eksperimento metu nebuvo jokių veiklos skirtumų tikslo atžvilgiu. Rezultatai aptariami remiantis nerimo ir kognityvinès veiklos teorijos bei kūrybiškumo pakopų modelio požiūriais.
\end{abstract}

Reikšminiai žodžiai: kūrybinè veikla, orientavimasis ị mokymosi tikslus, orientavimasis ị motyvuojančius tikslus, suvokimo veikla, orientavimasis ị suvokimo tikslus. 